\title{
An Evaluation of the Efficacy and Safety of Vibegron in the Treatment of Overactive Bladder
}

\author{
Jeffrey Frankel', David Staskin², Susann Varano ${ }^{3}$, Michael J Kennelly ${ }^{4}$, Rachael A Jankowich ${ }^{5}$, \\ Cornelia Haag-Molkenteller ${ }^{5}$
}

'Seattle Urology Research Center, Seattle, WA, USA; ${ }^{2}$ Tufts University School of Medicine, Boston, MA, USA; ${ }^{3}$ Clinical Research Consulting, Milford, CT, USA; ${ }^{4}$ Carolinas Medical Center, Charlotte, NC, USA; ${ }^{5}$ Urovant Sciences, Irvine, CA, USA

Correspondence: Jeffrey Frankel, PO Box I 192, Mercer Island, WA 98040, USA, Tel + I 206972 2775, Email jmfrankel@comcast.net

\begin{abstract}
Pharmacologic treatment for overactive bladder (OAB), which is characterized by bothersome symptoms such as urgency and urge urinary incontinence (UUI), includes anticholinergics and $\beta_{3}$-adrenergic receptor agonists. Anticholinergics are associated with adverse effects including dry mouth, constipation, cognitive impairment, and increased risk of dementia. Therefore, the drug class of $\beta_{3}$-adrenergic receptor agonists may represent an effective, safe treatment option. Vibegron, a $\beta_{3}$-adrenergic receptor agonist, was approved for use in Japan (2018) and the United States (2020). Over the past 3 years, 2 phase 3 trials (EMPOWUR, EMPOWUR extension) have been conducted with once-daily vibegron $75 \mathrm{mg}$ for the treatment of $\mathrm{OAB}$, and additional secondary and subgroup analyses have detailed the efficacy and safety of vibegron. In the international phase 3 EMPOWUR trial, treatment with vibegron was associated with significant improvements compared with placebo in efficacy outcomes of micturition frequency, UUI episodes, urgency episodes, and volume voided as early as week 2 that were sustained throughout the 12-week trial. The 40-week EMPOWUR extension study, following the 12-week treatment period, demonstrated sustained efficacy in patients receiving vibegron for 52 weeks. Treatment with vibegron was also associated with improvements in patient-reported measures of quality of life. Across studies, vibegron was generally safe and well tolerated. A separate, dedicated ambulatory blood pressure monitoring study showed that treatment with vibegron was not associated with clinically meaningful effects on blood pressure or heart rate. Across all studies, vibegron was efficacious, safe, and well tolerated and thus represents a valuable treatment option for patients with OAB. Here, nearly 1 year after US approval, we review the published data on efficacy and safety of vibegron $75 \mathrm{mg}$ for the treatment of OAB.
\end{abstract}

Keywords: adrenergic agonist, $\beta$-adrenergic receptor, urinary bladder overactive, urinary incontinence, vibegron

\section{Plain Language Summary}

Millions of adults worldwide have symptoms of overactive bladder. Overactive bladder can make a person feel like they need to urinate immediately and may be hard to control. Treatment for overactive bladder can include bladder training, but some patients take medication to help with their symptoms. Many medications exist, but some may cause side effects like dry mouth and constipation. Vibegron is a newer medication that works differently than older medications. In this review article, we discuss how well vibegron helped improve symptoms in clinical trials for patients with overactive bladder. Patients who took vibegron, including those over 65 years old, showed more improvement in their symptoms compared with patients who were given placebo (a pill with no medicine in it). Patients who took vibegron also had improved quality of life compared with patients who took a placebo. These studies showed that vibegron works well, is safe, and may be able to help patients who have overactive bladder manage their symptoms better.

\section{Introduction}

Overactive bladder $(\mathrm{OAB})$ is prevalent in an estimated 550 million individuals worldwide ${ }^{1}$ and is characterized by bothersome symptoms such as urgency with or without urge urinary incontinence (UUI). ${ }^{2,3}$ OAB affects both men and women, and prevalence increases with age; ${ }^{4}$ however, symptoms such as UUI may disproportionately affect women. ${ }^{5}$ Patients with $\mathrm{OAB}$ experience the urge to urinate, associated with stretching of the detrusor muscle, at a low bladder 
volume. ${ }^{6}$ The etiology of OAB is not fully understood, and the major cause may vary between patients. Models explaining the pathophysiology of OAB have been reviewed elsewhere. ${ }^{6}$

Behavioral therapy with or without oral pharmacologic therapies are first-line treatments for reducing the symptom burden associated with OAB. ${ }^{5}$ Second-line treatment includes oral pharmacologic agents, ${ }^{5}$ such as anticholinergics and $\beta_{3}$-adrenergic receptor agonists mirabegron and vibegron. However, anticholinergics are associated with adverse effects including cognitive impairment and increased risk of dementia. ${ }^{7,8}$ In addition, anticholinergic side effects such as dry mouth and constipation may limit treatment persistence. ${ }^{9,10}$ These effects increase with increasing anticholinergic burden, ${ }^{8,11}$ which is frequently seen in older adults who may encounter polypharmacy. ${ }^{12}$ It has also been reported that incidence of anticholinergic-related side effects is numerically higher when an anticholinergic is administered concomitantly with a $\beta_{3}$-adrenergic receptor agonist vs anticholinergic monotherapy. ${ }^{13-15}$ The emergence of $\beta_{3}$-adrenergic receptor agonists for the treatment of $\mathrm{OAB}$ demonstrated efficacy with a safety profile that was associated with a low incidence of adverse effects. ${ }^{16,17}$

$\beta_{1^{-}}, \beta_{2^{-}}$, and $\beta_{3^{-}}$-adrenergic receptors are structurally related G-protein coupled receptors with distinct expression patterns and functions. ${ }^{18} \beta_{3}$-adrenergic receptors are highly expressed in the urinary bladder and detrusor muscles; here, $\beta_{3}$-adrenergic receptors account for $94 \%$ to $97 \%$ of $\beta$-adrenergic receptor mRNA. ${ }^{19,20}$ Activation of the $\beta_{3}$-adrenergic receptor in the detrusor smooth muscle increases bladder capacity by relaxing the detrusor during bladder filling. ${ }^{19}$ However, $\beta$-adrenergic receptors (predominantly $\beta_{1}$ and $\beta_{2}$ ) are also expressed on cardiac tissue, ${ }^{21}$ potentiating concerns about off-target effects. Vibegron was intentionally pharmaceutically designed to be highly specific for the $\beta_{3}$-adrenergic receptor. ${ }^{22,23}$ In cell-based assays, both vibegron and mirabegron were highly selective at $\beta_{3}$-adrenergic receptors, ${ }^{24}$ however, vibegron showed no measurable $\beta_{1}$ and low $\beta_{2}$ activity compared with mirabegron, which showed measurable $\beta_{1}$ and some $\beta_{2}$ activity. Vibegron showed a higher maximum response at $\beta_{3}$-adrenergic receptors compared with mirabegron (99.2\% vs $80.4 \%$, respectively). ${ }^{24}$ Additionally, vibegron does not inhibit cytochrome P450 (CYP) 2D6 or other major CYP isoenzymes ${ }^{25,26}$ and thus may be less likely to be subject to clinically relevant drug-drug interactions ${ }^{27}$ than other medications that are CYP2D6 inhibitors such as mirabegron. ${ }^{28,29}$

Vibegron received approval for the treatment of OAB in adults in Japan $\left(\right.$ BEOVA $\left.^{\circledR}\right)$ in September 2018 at a 50-mg dose and in the United States (GEMTESA ${ }^{\circledR 25}$ ) in December 2020 at a $75-\mathrm{mg}$ dose. In the United States, vibegron $75 \mathrm{mg}$ is available as a once-daily treatment and can be swallowed whole with water or crushed and mixed with applesauce. ${ }^{25}$ In its US label, vibegron is indicated for the treatment of $\mathrm{OAB}$ with symptoms of urge urinary incontinence, urgency, and urinary frequency. ${ }^{25}$ Here, we review the efficacy and safety of once-daily vibegron $75 \mathrm{mg}$ for the treatment of OAB.

\section{Overview of Completed Trials}

The efficacy and safety of vibegron $75 \mathrm{mg}$ has been investigated for use in treating OAB across a 12-week, international, phase 3, randomized, double-blind, controlled trial (EMPOWUR) and a 52-week phase 3, randomized, double-blind, controlled extension trial (EMPOWUR extension; Table 1). ${ }^{16,30}$ The cardiovascular safety of vibegron was additionally assessed in a dedicated 28-day phase 1 ambulatory blood pressure monitoring (ABPM) trial. ${ }^{31}$ The ABPM trial included only placebo as a comparator because the focus was on blood pressure and heart rate compared with placebo. EMPOWUR included both placebo and active control (tolterodine $4 \mathrm{mg}$ extended release [ER]); because of ethical considerations, the EMPOWUR extension included only active control. Patients were women and men $\geq 18$ years old in the EMPOWUR and EMPOWUR extension studies (age range, 18-93 years). To ensure the patient population in EMPOWUR was representative of the realworld population, enrollment of male patients was capped at $15 \%$, and $\leq 25 \%$ of all patients could have OAB dry (without urinary incontinence at baseline). Women ultimately represented $85.2 \%$ of patients in EMPOWUR; $77.0 \%$ of all patients experienced $\mathrm{OAB}$ wet (with urinary incontinence at baseline), and $43.3 \%$ were $\geq 65$ years old. In the extension study, $78.2 \%$ were women, and $46.5 \%$ of all patients were $\geq 65$ years old. The EMPOWUR and EMPOWUR extension studies required participants to have a history of $\mathrm{OAB}$ for $\geq 3$ months and, based on a patient voiding diary, an average of $\geq 8$ micturitions per day, $\geq 1$ UUI episode per day for OAB wet, and $\geq 3$ urgency episodes per day for OAB dry. The phase 1 ABPM study included women (74.6\%) and men (25.4\%) 45 to 75 years old with OAB and did not require a voiding diary because the endpoints were focused on ambulatory blood pressure and not OAB symptoms. In the EMPOWUR study, efficacy assessments were measured as early as week 2 . Subgroup, secondary, and post hoc analyses of the primary EMPOWUR study 
Table I Overview of Primary Vibegron Studies

\begin{tabular}{|c|c|c|c|c|c|}
\hline Study & $\begin{array}{c}\text { Study } \\
\text { Duration }\end{array}$ & Study Type & $\begin{array}{c}\text { Experimental } \\
\text { Group* }\end{array}$ & $\begin{array}{l}\text { Control } \\
\text { Group* }\end{array}$ & Outcomes Assessed \\
\hline $\begin{array}{l}\text { Staskin et al } \\
2020^{16} \\
\text { EMPOWUR }\end{array}$ & $12 \mathrm{wk}$ & Phase 3 & $\begin{array}{l}\text { Vibegron } 75 \mathrm{mg} \\
\qquad(\mathrm{N}=545)\end{array}$ & $\begin{array}{l}\text { Placebo } \\
(\mathrm{N}=540) \\
\text { Tolterodine } \\
4 \mathrm{mg} \text { ER } \\
(\mathrm{N}=430)\end{array}$ & $\begin{array}{l}\text { Number of micturitions, UUl episodes, }{ }^{\dagger} \text { urgency episodes, } \\
\text { volume voided, proportion of patients with } \geq 75 \% \\
\text { reduction in UUl episodes }{ }^{\dagger} \\
\text { Safety }\end{array}$ \\
\hline $\begin{array}{l}\text { Staskin et al } \\
2021^{30} \\
\text { EMPOWUR } \\
\text { Extension }\end{array}$ & 52 wk & Phase 3 , extension & $\begin{array}{l}\text { Vibegron } 75 \mathrm{mg} \\
\qquad(\mathrm{N}=273)\end{array}$ & $\begin{array}{l}\text { Tolterodine } \\
4 \mathrm{mg} \text { ER } \\
(\mathrm{N}=232)\end{array}$ & $\begin{array}{c}\text { Micturitions, urgency episodes, UUI episodes, }{ }^{\dagger} \text { total } \\
\text { urinary incontinence episodes }{ }^{\dagger} \\
\text { Safety }\end{array}$ \\
\hline $\begin{array}{l}\text { Weber et al } \\
2021^{31}\end{array}$ & $28 d$ & $\begin{array}{l}\text { Phase I, } \\
\text { ambulatory blood } \\
\text { pressure } \\
\text { monitoring }\end{array}$ & $\begin{array}{l}\text { Vibegron } 75 \mathrm{mg} \\
\qquad(\mathrm{N}=106)\end{array}$ & $\begin{array}{l}\text { Placebo } \\
(\mathrm{N}=108)\end{array}$ & $\begin{array}{l}\text { Mean daytime and 24-hour ambulatory systolic blood } \\
\text { pressure, diastolic blood pressure, and heart rate } \\
\text { Safety }\end{array}$ \\
\hline
\end{tabular}

Notes: *Population numbers reported from the safety set, defined as all patients who received $\geq 1$ dose of double-blind study medication. ${ }^{\dagger}$ In patients with $O A B$ wet (defined as an average of $\geq 8$ micturitions and $\geq I U U I$ episode per day).

Abbreviations: $\mathrm{ER}$, extended release; $\mathrm{OAB}$, overactive bladder; $\mathrm{UUI}$, urge urinary incontinence.

(Table 2) included assessment of patient-reported outcomes, ${ }^{32}$ age subgroups ( $\geq 65$ years old and $\geq 75$ years old),${ }^{33}$ efficacy in patients with $\mathrm{OAB}$ dry (without urinary incontinence) vs $\mathrm{OAB}$ wet (with urinary incontinence), ${ }^{34}$ and efficacy and safety in women. ${ }^{35,36}$

The pivotal, phase 3 EMPOWUR trial was a 12-week, double-blind, placebo- and active-controlled trial that assessed the efficacy and safety of vibegron in adult patients with OAB (NCT03492281). ${ }^{16}$ In EMPOWUR, the coprimary

Table 2 Overview of Secondary, Post Hoc, and Subgroup Analyses of EMPOWUR

\begin{tabular}{|c|c|c|c|c|}
\hline Publication & Analysis & $\begin{array}{c}\text { Experimental } \\
\text { Group }\end{array}$ & Control Group & Outcomes Assessed \\
\hline $\begin{array}{l}\text { Frankel et al } \\
2020^{32}\end{array}$ & $\begin{array}{l}\text { Patient-reported QoL } \\
\text { outcomes }\end{array}$ & $\begin{array}{l}\text { Vibegron } 75 \mathrm{mg} \\
\qquad(\mathrm{N}=526)\end{array}$ & $\begin{array}{l}\text { Placebo }(\mathrm{N}=520) \\
\text { Tolterodine } 4 \mathrm{mg} \text { ER }(\mathrm{N}=4 \mid 7)\end{array}$ & OAB-q, PGI \\
\hline $\begin{array}{l}\text { Varano et al } \\
2021^{33}\end{array}$ & $\begin{array}{l}\text { Older adults ( } \geq 65 \text { years old, } \\
\quad \geq 75 \text { years old) }\end{array}$ & $\begin{array}{l}\geq 65 \text { years old } \\
\text { Vibegron } 75 \mathrm{mg} \\
\quad(\mathrm{N}=242) \\
\geq 75 \text { years old } \\
\text { Vibegron } 75 \mathrm{mg} \\
(\mathrm{N}=75)\end{array}$ & $\begin{array}{c}\geq 65 \text { years old } \\
\text { Placebo }(\mathrm{N}=220) \\
\text { Tolterodine } 4 \mathrm{mg} \text { ER }(\mathrm{N}=166) \\
\geq 75 \text { years old } \\
\text { Placebo }(\mathrm{N}=57) \\
\text { Tolterodine } 4 \mathrm{mg} \text { ER }(\mathrm{N}=47)\end{array}$ & $\begin{array}{c}\text { Micturitions, urgency episodes, UUI } \\
\text { episodes* } \\
\text { Responder analyses: Percentage of } \\
\text { patients with } \geq 75 \% \text { reduction in UUI } \\
\text { episodes* and with } \geq 50 \% \text { reduction in } \\
\text { urgency episodes } \\
\text { Safety }\end{array}$ \\
\hline $\begin{array}{l}\text { Staskin et al } \\
2021^{30}\end{array}$ & Efficacy in $O A B$ wet vs dry & $\begin{array}{c}\text { OAB wet } \\
\text { Vibegron } 75 \mathrm{mg} \\
(\mathrm{N}=403) \\
\text { OAB dry } \\
\text { Vibegron } 75 \mathrm{mg} \\
(\mathrm{N}=123)\end{array}$ & $\begin{array}{c}\text { OAB wet } \\
\text { Placebo }(\mathrm{N}=405) \\
\text { Tolterodine } 4 \mathrm{mg} \text { ER }(\mathrm{N}=3 \mid 9) \\
\text { OAB dry } \\
\text { Placebo }(\mathrm{N}=\mid \mathrm{I}) \\
\text { Tolterodine } 4 \mathrm{mg} \text { ER }(\mathrm{N}=98)\end{array}$ & Urgency episodes, micturitions \\
\hline $\begin{array}{l}\text { Varano et al } \\
2021^{36}\end{array}$ & Efficacy and safety in women & $\begin{array}{l}\text { Vibegron } 75 \mathrm{mg} \\
\qquad(\mathrm{N}=463)\end{array}$ & $\begin{array}{l}\text { Placebo }(\mathrm{N}=459) \\
\text { Tolterodine } 4 \mathrm{mg} \text { ER }(\mathrm{N}=364)\end{array}$ & $\begin{array}{c}\text { Micturitions, urgency episodes, UUI } \\
\text { episodes* } \\
\text { Safety }\end{array}$ \\
\hline
\end{tabular}

Notes: *In patients with $O A B$ wet (defined as an average of $\geq 8$ micturitions and $\geq$ I UUl episode per day).

Abbreviations: ER, extended release; OAB, overactive bladder; OAB-q, OAB questionnaire; PGI, patient global impression; QoL, quality of life; UUI, urge urinary incontinence. 
endpoints were change from baseline to week 12 in average daily number of micturitions and in average daily number of UUI episodes (patients with OAB wet only). Key secondary endpoints included change from baseline to week 12 in average daily number of urgency episodes, average daily volume voided per micturition, and the percentage of patients with $\mathrm{OAB}$ wet reporting $\geq 75 \%$ reduction in average daily number of UUI episodes. Safety was assessed through adverse event (AE) reporting.

In addition to the primary EMPOWUR analyses, publications arising from the EMPOWUR study include patientreported quality of life (QoL) measures, ${ }^{32}$ efficacy and safety in older adults, ${ }^{33}$ efficacy in patients with OAB wet vs $\mathrm{OAB}$ dry, ${ }^{34}$ and efficacy and safety in women. ${ }^{36}$ Patient-reported QoL was assessed through the OAB-questionnaire (OAB-q), which included a health-related QoL (HRQL) score (consisting of subscales for coping, concern, sleep, and social interaction) and symptom bother score, as well as the patient global impression (PGI) of severity, control, frequency, leakage, and change.

Patients who completed the EMPOWUR trial could enroll in the EMPOWUR extension trial (NCT03583372). ${ }^{30}$ The EMPOWUR extension was a 40-week-long study to investigate the long-term efficacy and safety of vibegron. Patients who received vibegron or active control (tolterodine $4 \mathrm{mg}$ ER) for 12 weeks in EMPOWUR continued with the same treatment for the next 40 weeks of the study; patients who received placebo in EMPOWUR were randomly assigned 1:1 to receive vibegron or active control. The primary endpoint was safety, assessed by AE reporting. Secondary endpoints included change from baseline at week 52 in average daily number of micturitions, UUI episodes, urgency episodes, and total urinary incontinence episodes.

ABPM is a sensitive method used to detect small changes in blood pressure $(2-3 \mathrm{mmHg})$ and in heart rate and is an important aspect for drugs in development. The phase 1 ABPM study was conducted to compare the blood pressure and heart rate effect profile of once-daily vibegron $75 \mathrm{mg}$ compared with placebo in patients with $\mathrm{OAB} .{ }^{31}$ The primary endpoint in this study was change from baseline to day 28 in mean daytime (waking hours) ambulatory systolic blood pressure. Key secondary endpoints were change from baseline to day 28 in mean daytime ambulatory diastolic blood pressure and heart rate and in mean 24-hour ambulatory systolic blood pressure, diastolic blood pressure, and heart rate. In this trial, safety was assessed through $\mathrm{AE}$ reporting, laboratory assessments, and in-clinic vital signs.

\section{Efficacy}

\section{Short-Term Efficacy}

In EMPOWUR, statistically significant improvements from baseline were seen at week 12 with vibegron vs placebo for average daily number of micturitions (least squares [LS] mean, -1.8 vs -1.3 , respectively; $P<0.001$; Figure 1 ) and UUI episodes $(-2.0$ vs $-1.4 ; P<0.0001) .{ }^{16}$ Additionally, statistically significant improvements were seen with vibegron compared with placebo in the average daily number of urgency episodes $(-2.7 \mathrm{vs}-2.0)$, average volume voided per micturition ( $23.5 \mathrm{vs} 2.2 \mathrm{~mL}$ ), and percentage of patients achieving a $\geq 75 \%$ reduction in average daily number of UUI episodes (49.3\% vs $32.8 \%$; $P<0.01$, all). Statistically significant improvements in efficacy were seen with vibegron treatment as early as week 2 for all coprimary and evaluated key secondary endpoints (urgency episodes, volume voided, and percentage of patients experiencing a $\geq 75 \%$ reduction in average daily number of UUI episodes). A subgroup analysis in women showed reductions from baseline at week 12 in micturitions ( -1.9 vs -1.4$)$, UUI episodes ( -2.1 vs -1.4$)$, and urgency episodes $(-2.8$ vs -1.9$)$ with vibegron vs placebo that were comparable with the overall population. ${ }^{36}$

The symptoms associated with OAB can cause significant emotional and psychological impact, ${ }^{37}$ and patient-reported outcomes represent an important way to assess improvement that may be more meaningful to patients. As part of the EMPOWUR trial, the OAB-q and PGI were used to assess QoL, and these results were presented in a subsequent publication. ${ }^{32}$ Treatment with vibegron was associated with significant improvements compared with placebo at week 12 in OAB-q HRQL total score (including coping, concern, and sleep subscales) and symptom bother score ( $P<0.01$ each), as well as PGI measures of severity, control, frequency, leakage, and change ( $P<0.001$ each). Greater proportions of patients receiving vibegron compared with placebo reported the best possible responses to individual PGI measures (responses ranged from much worse to much better; $P<0.05$ each). 
A

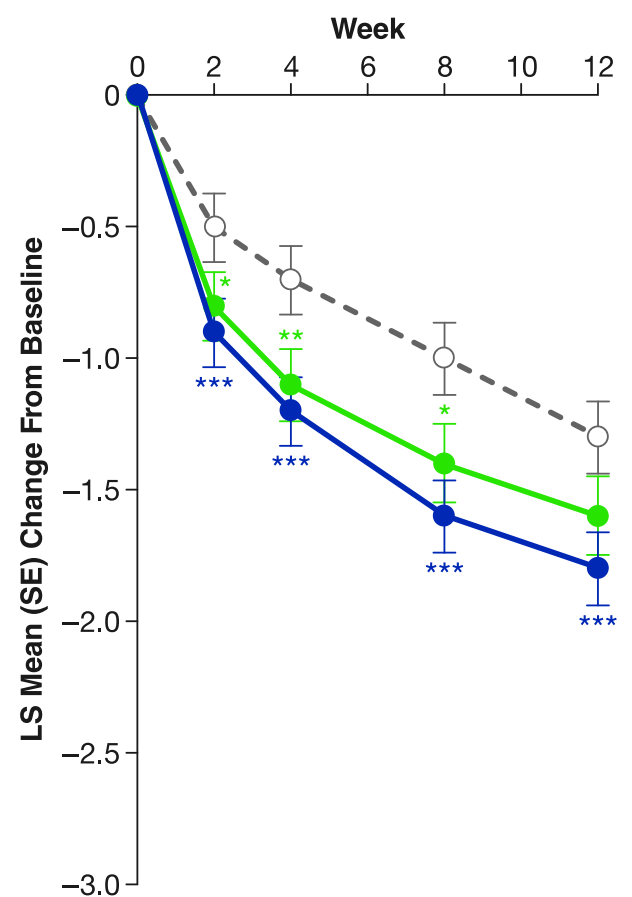

B

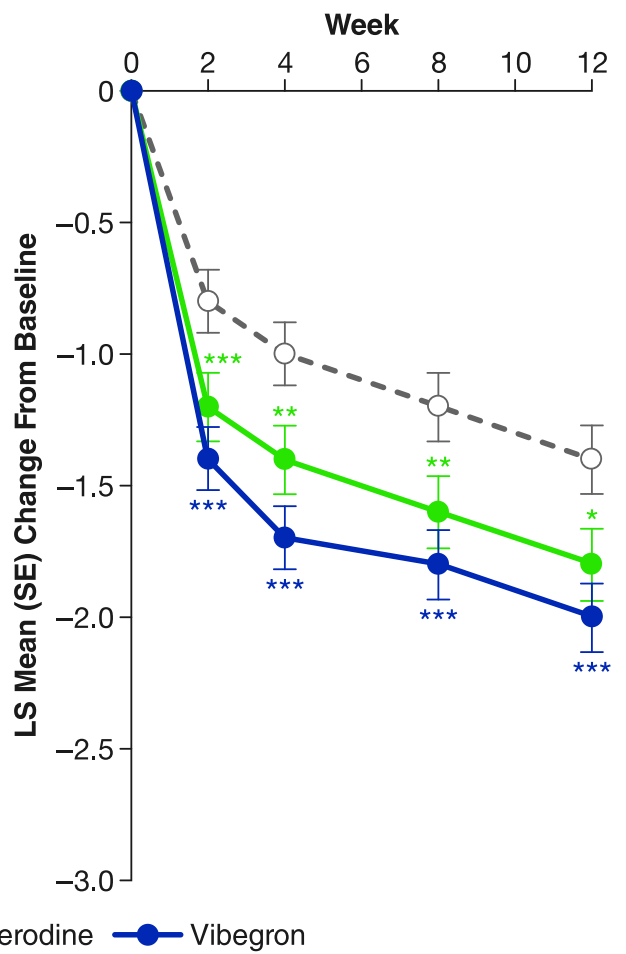

Figure I LS mean change from baseline in average daily number of $(\mathbf{A})$ micturitions and (B) UUI episodes over 12 weeks. $* P<0.05$. $* * P<0.0 \mathrm{I}$. $* * * P<0.00$ I vs placebo. Reprinted with permission from Wolters Kluwer Health, Inc.: Staskin D, Frankel J, Varano S, Shortino D, Jankowich R, Mudd PN, Jr. International phase III, randomized, double-blind, placebo and active controlled study to evaluate the safety and efficacy of vibegron in patients with symptoms of overactive bladder: EMPOWUR. $J$ Urol. 2020;204(2):316-324. Available from: https://www.auajournals.org/doi// 0.1097/JU.0000000000000807. ${ }^{16}$

Abbreviations: LS, least squares; UUI, urge urinary incontinence.

As OAB prevalence increases with age, ${ }^{2}$ a subpopulation analysis of the phase 3 EMPOWUR trial specifically evaluated the efficacy and safety in adults $\geq 65$ and $\geq 75$ years old (Table 3 ). In the older adult population, treatment with vibegron was associated with significant reductions from baseline at week 12 vs placebo in average daily number of micturitions (LS mean: $\geq 65$ years, -1.9 vs -1.0 , respectively; $\geq 75$ years, -2.1 vs $-1.2 ; P<0.05$ each), UUI episodes ( $\geq 65$ years, -2.0 vs $-1.2 ; \geq 75$ years, -2.0 vs $-0.4 ; P<0.001$ each), and urgency episodes ( $\geq 65$ years, -2.7 vs $-1.7 ; \geq 75$ years, -2.6 vs $-0.9 ; P<0.01$ each), suggesting that treatment with vibegron is efficacious in these populations. Significantly more patients $\geq 65$ years old (population including those $\geq 75$ years old) treated with vibegron vs placebo experienced $\geq 75 \%$ reduction in UUI episodes $(P<0.0001)$ and a $50 \%$ reduction in urgency episodes $(P<0.05)$.

In a post hoc analysis of the efficacy of vibegron in patients with or without urinary incontinence at baseline, referred to as $\mathrm{OAB}$ wet vs $\mathrm{OAB}$ dry, respectively, treatment with vibegron was associated with significant reductions from baseline at week 12 compared with placebo in average daily urgency episodes (LS mean: wet, $-3.0 \mathrm{vs}-2.4$, respectively; dry, -2.6 vs -1.6$)$ and micturition frequency (wet, -2.1 vs -1.7 ; dry, -1.8 vs -1.0$)$ in both populations ( $P<0.05$ each). Significant reductions in urgency episodes were seen with vibegron vs placebo as early as week 2 and were maintained throughout the 12-week trial for the wet and dry populations $(P<0.05$ each).

\section{Long-Term Efficacy}

Continued treatment with vibegron $75 \mathrm{mg}$ for an additional 40 weeks (52 weeks total) was associated with significant improvements from baseline compared with tolterodine in average daily number of UUI (LS mean, -2.2 vs -1.7 , respectively; $P<0.05$; Figure 2$)$ and total urinary incontinence episodes $(-2.5 \mathrm{vs}-1.9 ; P<0.05$; Figure 3$) .{ }^{30}$ Additionally, sustained reductions from baseline were seen in average daily urgency episodes throughout the 52-week trial (Figure 3). In a post hoc analysis, patients who received placebo in EMPOWUR and vibegron in the extension study (40 weeks of 
Table 3 Key Patient Baseline Demographics and Clinical Characteristics of Patients $\geq 65$ Years Old (a Subpopulation Analysis from the EMPOWUR Trial)

\begin{tabular}{|c|c|c|c|c|}
\hline Characteristic & Placebo & Vibegron 75 mg & Tolterodine 4 mg ER & Overall \\
\hline Full Analysis Set, $\mathbf{N}$ & 220 & 242 & 166 & 628 \\
\hline Women, n (\%) & I78 (80.9) & $204(84.3)$ & $132(79.5)$ & $514(81.8)$ \\
\hline Men, n (\%) & $42(19.1)$ & $38(15.7)$ & $34(20.5)$ & $114(18.2)$ \\
\hline Mean (SD) age, $y$ & $71.8(5.39)$ & $71.8(5.59)$ & $72.0(5.43)$ & $71.9(5.47)$ \\
\hline Age $\geq 75$ y, n (\%) & $57(25.9)$ & $75(31.0)$ & $47(28.3)$ & $179(28.5)$ \\
\hline \multicolumn{5}{|l|}{ Race, n (\%) } \\
\hline White & I $76(80.0)$ & 197 (8I.4) & I 29 (77.7) & $502(79.9)$ \\
\hline Black or African American & $19(8.6)$ & $26(10.7)$ & $19(11.4)$ & $64(10.2)$ \\
\hline Asian & $23(10.5)$ & $19(7.9)$ & $17(10.2)$ & $59(9.4)$ \\
\hline Other & $2(0.9)$ & 0 & I (0.6) & $3(0.5)$ \\
\hline \multicolumn{5}{|l|}{ Region, n (\%) } \\
\hline US & $190(86.4)$ & $218(90.1)$ & $150(90.4)$ & $558(88.9)$ \\
\hline Non-US & $30(13.6)$ & $24(9.9)$ & $16(9.6)$ & $70(11.1)$ \\
\hline Safety Set,* N & 228 & 246 & $|7|$ & 645 \\
\hline \multicolumn{5}{|l|}{ Medical history (conditions of interest), $\mathrm{n}(\%)$} \\
\hline Hypertension $^{\dagger}$ & I34 (58.8) & $155(63.0)$ & $120(70.2)$ & $409(63.4)$ \\
\hline Osteoarthritis & $64(28.1)$ & $76(30.9)$ & $59(34.5)$ & $199(30.9)$ \\
\hline Gastroesophageal reflux & $59(25.9)$ & $65(26.4)$ & $48(28.1)$ & $172(26.7)$ \\
\hline Diabetes mellitus & $12(5.3)$ & $15(6.1)$ & $10(5.8)$ & $37(5.7)$ \\
\hline \multicolumn{5}{|l|}{ Concomitant non-OAB medications, ${ }^{\ddagger}$ n (\%) } \\
\hline Agents acting on the renin-angiotensin system & $99(43.4)$ & $112(45.5)$ & $81(47.4)$ & $292(45.3)$ \\
\hline Lipid-modifying agents & $96(42.1)$ & $101(4 I .1)$ & $80(46.8)$ & $277(42.9)$ \\
\hline Vitamins & 87 (38.2) & $89(36.2)$ & $59(34.5)$ & $235(36.4)$ \\
\hline
\end{tabular}

Notes: *Patients in the safety set were excluded from the full analysis set for one or more reasons (ie, they did not have a baseline or $\geq \mathrm{I}$ post-baseline micturition assessment or they did not receive double-blind study medication). ${ }^{\dagger}$ Pre-existing hypertension was based on baseline vitals and medical history. ${ }^{\ddagger}$ Within the past 12 months. Abbreviations: ER, extended release; OAB, overactive bladder.

treatment with vibegron) also experienced reductions from baseline in average daily number of micturitions, UUI episodes, urgency episodes, and total urinary incontinence episodes. In exploratory responder analyses, greater percentages of patients with $\mathrm{OAB}$ wet receiving vibegron for 52 weeks compared with tolterodine reported $\geq 50 \%$ reductions in total urinary incontinence episodes $(71.1 \%$ vs $61.9 \%$, respectively) and $\geq 75 \%$ reductions in UUI episodes $(61.0 \%$ vs $54.4 \%)$. Additionally, a greater percentage of patients receiving vibegron (40.8\%) compared with tolterodine (34.2\%) experienced $\geq 100 \%$ reduction in UUI episodes (ie, were dry).

\section{Safety}

\section{Overall Safety and Tolerability}

Vibegron was well tolerated in the clinical trials. The study completion rate was $90 \%$ after 12 weeks of treatment with vibegron in EMPOWUR. In the EMPOWUR extension study, both those continuing treatment with vibegron (52 weeks of treatment) and those switching from placebo to vibegron (40 weeks of treatment) had completion rates of $86 \%$. Discontinuations due to AEs were low and comparable with placebo in the EMPOWUR study $(1.7 \%$ with vibegron vs $1.1 \%$ with placebo) and were lower than tolterodine in the EMPOWUR extension study $(1.5 \%$ with vibegron vs $3.4 \%$ with tolterodine). In the ABPM study, the rate of study completion was $97 \%$ for both vibegron and placebo.

Serious AEs occurred at rates comparable with placebo (1.5\% vs $1.1 \%$ for vibegron vs placebo, respectively) in EMPOWUR and with tolterodine (3.3\% vs $4.3 \%$ for vibegron vs tolterodine, respectively) in the EMPOWUR extension. In EMPOWUR, the most frequently occurring treatment-emergent AEs (TEAEs) with incidence greater with vibegron than placebo were headache and nasopharyngitis (Table 4). Incidence of hypertension was similar between vibegron and 


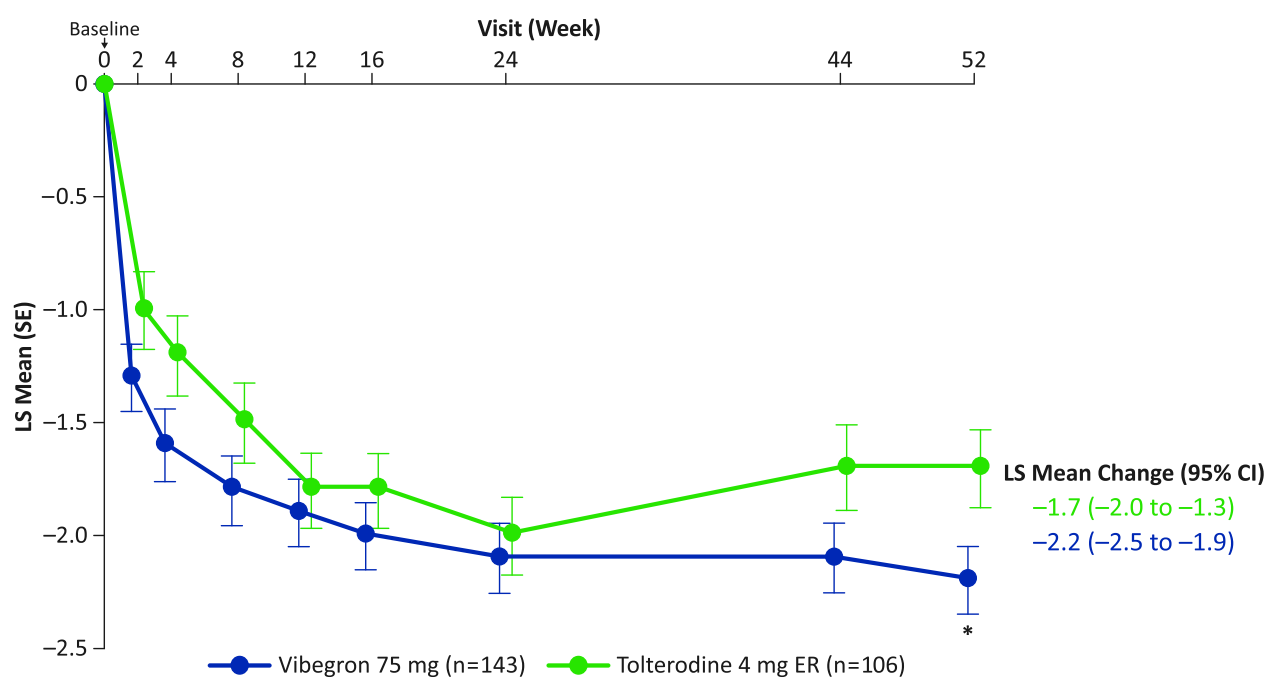

Figure 2 LS mean change from baseline in average daily number of UUI episodes over 52 weeks. *P < 0.05 . Reprinted with permission from Wolters Kluwer Health, Inc.: Staskin D, Frankel J, Varano S, Shortino D, Jankowich R, Mudd PN, Jr. Once-daily vibegron $75 \mathrm{mg}$ for overactive bladder: long-term safety and efficacy from a double-blind extension study of the international phase 3 trial (EMPOWUR). J Urol. 202I;205(5):|42I-I429. Available from: https://www.auajournals.org/doi/I0.I097/JU. $0000000000001574 .^{30}$

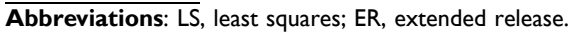

placebo treatment groups. In the EMPOWUR extension, the most common TEAEs with vibegron were hypertension (incidence similar to active control, tolterodine), UTI, and headache (Table 5). In the ABPM study, the most frequently occurring TEAEs with vibegron were hypertension, URTI, and headache. Drug hypersensitivity was reported as a TEAE in 2 patients $(0.4 \%)$ receiving vibegron in EMPOWUR; no patients reported a TEAE of drug hypersensitivity in the EMPOWUR extension. In EMPOWUR and the EMPOWUR extension, rates of dry mouth, a commonly occurring anticholinergic-related $\mathrm{AE}$, were lower with vibegron (1.7\% and $1.8 \%$, respectively) than with tolterodine $(6.5 \%$ and $5.2 \%$, respectively). The incidence of TEAE of urinary retention was infrequently observed in the 12-week EMPOWUR and 40-week EMPOWUR extension trials, occurring in 3 of 545 ( 2 men, 1 woman) and 3 of 273 (2 men, 1 woman) patients with vibegron, respectively. One man who experienced an AE of urinary retention reported the AE on the day he started the extension trial, and therefore the AE was included in both trials. In addition, no clinically meaningful changes in postvoid residual volume were observed with vibegron in the EMPOWUR or EMPOWUR extension studies. Urinary retention has been reported in patients taking vibegron, and the full prescribing information for vibegron includes a precaution to monitor for urinary retention, particularly in patients with bladder outlet obstructions and patients taking anticholinergic medications for $\mathrm{OAB}$, who may be at greater risk for experiencing urinary retention.

In the EMPOWUR age subgroup analysis, the most common TEAEs occurring with vibegron at a rate greater than placebo for the $\geq 65$-year-old subgroup were headache, dry mouth, and upper respiratory tract infection (URTI) and in the $\geq 75$-year-old subgroup were UTI, URTI, diarrhea, and dyspnea. Similar to the overall safety results, rates of dry mouth in patients $\geq 65$ years old were lower with vibegron (3.3\%) compared with tolterodine (7.0\%). In a post hoc analysis of safety in women, women receiving vibegron displayed a slightly higher incidence of headache, nasopharyngitis, and nausea compared with those receiving placebo; however, the overall incidence was consistent with the results of the EMPOWUR study.

There was 1 death reported in the EMPOWUR study in the tolterodine group (cerebrovascular accident; not considered treatment related by the investigator) and 1 death reported in the EMPOWUR extension study in the vibegron group (arteriosclerotic cardiovascular disease; not considered treatment related by the investigator). In the ABPM study, there were no deaths nor study treatment-related serious TEAEs. 


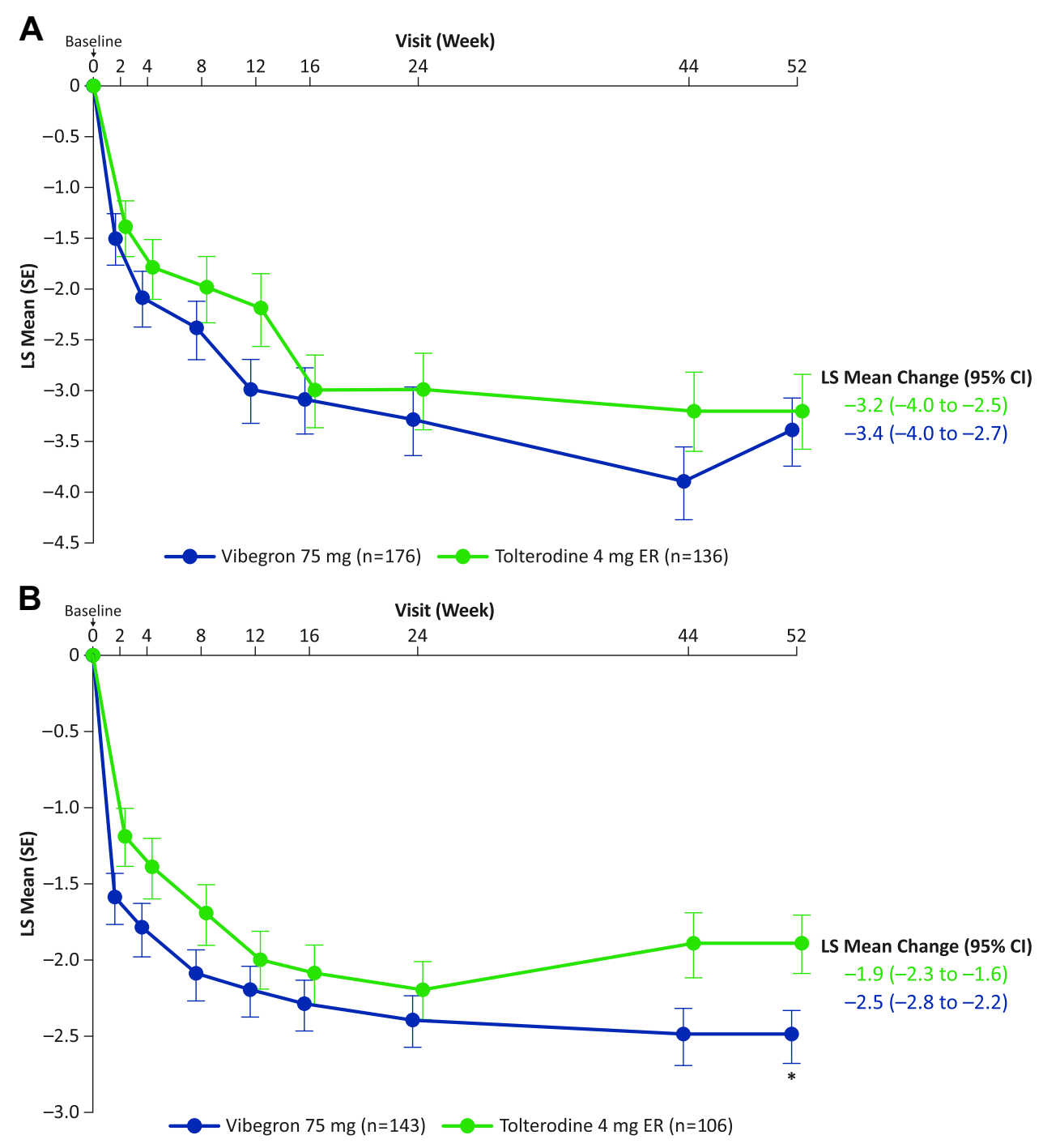

Figure 3 LS mean change from baseline in average daily number of $(\mathbf{A})$ urgency episodes and $(\mathbf{B})$ total urinary incontinence episodes over 52 weeks. $* P<0.05$. Reprinted with permission from Wolters Kluwer Health, Inc.: Staskin D, Frankel J, Varano S, Shortino D, Jankowich R, Mudd PN, Jr. Once-daily vibegron 75 mg for overactive bladder: long-term safety and efficacy from a double-blind extension study of the international phase 3 trial (EMPOWUR). J Urol. 202I;205(5): I42I-I429. Available from: https://www. auajournals.org/doi/10.1097/JU.0000000000001574. ${ }^{30}$

Abbreviations: LS, least squares; ER, extended release.

\section{Cardiovascular Safety}

In EMPOWUR, the rate of AEs of hypertension was low overall and comparable between groups (vibegron, $1.7 \%$; placebo, 1.7\%; tolterodine, 2.6\%), and the rate of AEs of blood pressure increase was similarly low (vibegron, $0.7 \%$; placebo, $0.9 \%$; tolterodine, $1.9 \%$ ). In the extension study, the rate of AEs of hypertension was similar between vibegron and tolterodine ( $8.8 \%$ vs $8.6 \%$, respectively), and the rate of AEs of blood pressure increase were reported in $0.7 \%$ with vibegron and $1.7 \%$ with tolterodine. In EMPOWUR, atrial fibrillation occurred in 1 patient each from the placebo, vibegron, and tolterodine groups (all in patients $\geq 65$ years old) and in the extension study was not observed with vibegron compared with 2 patients receiving tolterodine. Hypertension was the most commonly reported TEAE in the ABPM study, occurring in 5 of 106 (4.7\%) patients in the vibegron group compared with 4 of $108(3.7 \%)$ in the placebo group. One patient who experienced a TEAE of hypertension with vibegron was taking a prohibited medication known to increase blood pressure (phentermine). Furthermore, no events of hypertension with vibegron were considered related to study treatment. 
Table 4 Adverse Events by Treatment Group in the EMPOWUR Trial (Safety Analysis Set)

\begin{tabular}{|c|c|c|c|}
\hline & Placebo & Vibegron & Tolterodine \\
\hline No. pts & 540 & 545 & 430 \\
\hline \multicolumn{4}{|l|}{ No. summary (\%) } \\
\hline Any AE & $180(33.3)$ & $211(38.7)$ & $166(38.6)$ \\
\hline Any $A E$ of clinical interest & $40(7.4)$ & $36(6.6)$ & $38(8.8)$ \\
\hline Any serious $A E$ & $6(1.1)$ & $8(1.5)$ & $10(2.3)$ \\
\hline Any $A E$ leading to treatment discontinuation & $6(1.1)$ & $9(1.7)$ & $14(3.3)$ \\
\hline \multicolumn{4}{|l|}{ No. by $\mathrm{AE}$ preferred term (\%)* } \\
\hline Urinary tract infection & $33(6.1)$ & $27(5.0)$ & $25(5.8)$ \\
\hline Headache & $13(2.4)$ & $22(4.0)$ & II (2.6) \\
\hline Nasopharyngitis & $9(1.7)$ & $15(2.8)$ & II (2.6) \\
\hline Diarrhea & $6(1.1)$ & $12(2.2)$ & $9(2.1)$ \\
\hline Nausea & $6(1.1)$ & $12(2.2)$ & $5(1.2)$ \\
\hline Upper respiratory tract infection & $4(0.7)$ & II (2.0) & $2(0.5)$ \\
\hline Constipation & $7(1.3)$ & $9(1.7)$ & $6(1.4)$ \\
\hline Dry mouth & $5(0.9)$ & $9(1.7)$ & $28(6.5)$ \\
\hline Hypertension & $9(1.7)$ & $9(1.7)$ & II (2.6) \\
\hline Dizziness & $6(1.1)$ & $5(0.9)$ & $4(0.9)$ \\
\hline Blood pressure increased & $5(0.9)$ & $4(0.7)$ & $8(1.9)$ \\
\hline Urinary retention & $2(0.4)$ & $3(0.6)$ & $3(0.7)$ \\
\hline Fatigue & $5(0.9)$ & $2(0.4)$ & $6(1.4)$ \\
\hline Alanine aminotransferase increased & $2(0.4)$ & $\mathrm{I}(0.2)$ & $\mathrm{I}(0.2)$ \\
\hline Aspartate aminotransferase increased & $\mathrm{I}(0.2)$ & $\mathrm{I}(0.2)$ & $\mathrm{I}(0.2)$ \\
\hline Cardiac failure congestive & 0 & $\mathrm{I}(0.2)$ & 0 \\
\hline Cerebrovascular accident & 0 & $\mathrm{I}(0.2)$ & $\mathrm{I}(0.2)$ \\
\hline Cystitis & $\mathrm{I}(0.2)$ & $\mathrm{I}(0.2)$ & $\mathrm{I}(0.2)$ \\
\hline Hypotension & $\mathrm{I}(0.2)$ & $\mathrm{I}(0.2)$ & $\mathrm{I}(0.2)$ \\
\hline Blood pressure diastolic increased & 0 & 0 & $\mathrm{I}(0.2)$ \\
\hline Chest pain & $3(0.6)$ & 0 & 0 \\
\hline Escherichia urinary tract infection & 0 & 0 & $\mathrm{I}(0.2)$ \\
\hline Pollakiuria & $\mathrm{I}(0.2)$ & 0 & 0 \\
\hline Syncope & $2(0.4)$ & 0 & $\mathrm{I}(0.2)$ \\
\hline
\end{tabular}

Notes: *Includes all AEs with an incidence of $2.0 \%$ or greater in the vibegron group and greater than for placebo, plus all protocol-defined AEs of clinical interest. Reprinted with permission from Wolters Kluwer Health, Inc.: Staskin D, Frankel J, Varano S, Shortino D, Jankowich R, Mudd $\mathrm{PN}$, Jr. International phase III, randomized, double-blind, placebo and active controlled study to evaluate the safety and efficacy of vibegron in patients with symptoms of overactive bladder: EMPOWUR. J Urol. 2020;204(2):316-324. Available from: https://www.auajournals.org/doi//0. 1097/JU.0000000000000807. ${ }^{16}$

Abbreviation: $\mathrm{AE}$, adverse event.

In the dedicated ABPM study, the primary endpoint was change from baseline to day 28 in mean daytime systolic blood pressure. There was no statistically significant increase associated with vibegron treatment compared with placebo (LS mean, 0.82 vs $0.01 \mathrm{mmHg}$, respectively). The primary endpoint was evaluated against an upper bound of the $90 \%$ CI of $3.5 \mathrm{mmHg}$, and the actual upper bound was $<2.5 \mathrm{mmHg}$, providing strong evidence that vibegron does not lead to clinically significant changes in blood pressure. Additionally, there were no statistically significant increases in mean daytime diastolic blood pressure $(0.50 \mathrm{vs} 0.55 \mathrm{mmHg})$ or heart rate $(1.08 \mathrm{vs} 0.19 \mathrm{bpm})$ after 28 days of treatment with vibegron compared with placebo. No significant differences were seen between vibegron and placebo for the mean changes from baseline in 24-hour systolic blood pressure $(0.60 \mathrm{vs} 0.03 \mathrm{mmHg})$, diastolic blood pressure ( 0.51 vs 0.70 $\mathrm{mmHg})$, or heart rate $(0.80 \mathrm{vs}-0.15 \mathrm{bpm})$. The mean changes from baseline were similar in patients with or without preexisting hypertension. In sum, treatment with once-daily vibegron $75 \mathrm{mg}$ was not associated with clinically meaningful or statistically significant changes in blood pressure or heart rate. 
Table 5 Adverse Events by Treatment Group in the EMPOWUR Extension Trial (Safety Set Extension)

\begin{tabular}{|l|c|c|}
\hline & Vibegron & Tolterodine \\
\hline No. pts & 273 & 232 \\
No. $\geq I$ treatment-emergent AE (\%) & $171(62.6)$ & $126(54.3)$ \\
No. discontinued study medication due to AE & $4(1.5)$ & $8(3.4)$ \\
No. $\geq I$ treatment-emergent SAE (\%) & $9(3.3)$ & $10(4.3)$ \\
No. SAEs resulting in death (\%) & $1(0.4)^{*}$ & 0 \\
No. SAEs considered treatment-related by investigator ${ }^{\dagger}$ & $1(0.4)$ & $2(0.9)$ \\
No. AEs >2\% in either treatment group (\%) & & \\
Hypertension ${ }^{\ddagger}$ & $24(8.8)$ & $20(8.6)$ \\
Urinary tract infection & $18(6.6)$ & $17(7.3)$ \\
Headache & $15(5.5)$ & $9(3.9)$ \\
Diarrhea & $13(4.8)$ & $4(1.7)$ \\
Nasopharyngitis & $13(4.8)$ & $12(5.2)$ \\
Constipation & $10(3.7)$ & $6(2.6)$ \\
Nausea & $10(3.7)$ & $7(3.0)$ \\
Upper respiratory tract infection & $10(3.7)$ & $1(0.4)$ \\
Bronchitis & $8(2.9)$ & $3(1.3)$ \\
Anemia & $7(2.6)$ & $2(0.9)$ \\
Hyperglycemia & $7(2.6)$ & $2(0.9)$ \\
Residual urine volume increased & $7(2.6)$ & $3(1.3)$ \\
Back pain & $6(2.2)$ & $3(1.3)$ \\
Musculoskeletal pain & $6(2.2)$ & $1(0.4)$ \\
Dry mouth & $5(1.8)$ & $12(5.2)$ \\
\hline
\end{tabular}

Notes: *Arteriosclerotic disease, judged not related to the study drug by investigators and sponsor. 'Vibegron: collagenous colitis; tolterodine: syncope and cardiac failure. ${ }^{\ddagger}$ Defined as SBP $\geq 140 \mathrm{~mm} \mathrm{Hg}$ or DBP $\geq 90 \mathrm{~mm} \mathrm{Hg}$ (or both) at 2 consecutive visits in patients without baseline hypertension; an increase in SBP by $\geq 20 \mathrm{~mm} \mathrm{Hg}$ or DBP by $\geq 10 \mathrm{~mm} \mathrm{Hg}$ at 2 consecutive visits in patients with baseline hypertension; or the initiation of or increase in dose of medication for the treatment of hypertension in any patient. Reprinted with permission from Wolters Kluwer Health, Inc.: Staskin D, Frankel J, Varano S, Shortino D, Jankowich R, Mudd PN, Jr. Once-daily vibegron $75 \mathrm{mg}$ for overactive bladder: long-term safety and efficacy from a double-blind extension study of the international phase 3 trial (EMPOWUR). J Urol. 2021;205(5):|142I-1429. Available from:https://www.auajournals.org/ doi/I0.1097/JU.0000000000001574. ${ }^{30}$

Abbreviations: AE, adverse event; DBP, diastolic blood pressure; SAE, serious adverse event; SBP, systolic blood pressure.

\section{Conclusion}

Vibegron is the newest approved medication in the class of $\beta_{3}$-adrenergic receptor agonists used to treat patients with OAB. In 2 phase 3 trials, once-daily vibegron $75 \mathrm{mg}$ was associated with significant reductions in key symptoms of OAB. In 1 phase 1 28-day ABPM study, treatment with vibegron $75 \mathrm{mg}$ was not associated with statistically significant or clinically meaningful effects on blood pressure or heart rate. Treatment with vibegron was overall safe and well tolerated in older adults, women, and patients with or without urinary incontinence. The safety profile of vibegron lacks some of the bothersome side effects associated with anticholinergics, suggesting that treatment with vibegron may lead to improvements in persistence. Improvements in patient-reported QoL measures suggest that vibegron achieves both objective measures of clinical efficacy and subjective measures of symptomatic improvement that may be perceived as more meaningful by patients. Improvements associated with treatment with vibegron seen in women were consistent with those observed in the overall population. Overall, older adults, regardless of sex or OAB type, tolerated vibegron well, suggesting the potential to successfully use vibegron for OAB across varying populations. These combined data suggest that vibegron is a valuable addition to the repertoire of treatments for OAB. Further investigation into the real-world effectiveness of vibegron is warranted based on the promising efficacy and safety data seen in clinical trials. 


\section{Acknowledgments}

Medical writing and editorial support was provided by Wendy Kandell, $\mathrm{PhD}$, and Krystina Neuman, $\mathrm{PhD}, \mathrm{CMPP}$, of The Curry Rockefeller Group, LLC (Tarrytown, NY), and was funded by Urovant Sciences, Inc. (Irvine, CA).

\section{Disclosure}

J Frankel is an investigator for Urovant Sciences, an investigator and speaker for Astellas Pharma and Pfizer Inc, and a speaker for Tolmar Inc. D Staskin is an investigator and consultant for Urovant Sciences; a consultant, investigator, and speaker for Astellas Pharma; and a consultant for New Uro B.V. S Varano is principal investigator for Clinical Research Consulting, holds academic positions at Sacred Heart University and University of Bridgeport, and is paid consultant and speaker for Urovant Sciences. M J Kennelly has received grant and/or research study funding from Allergan, Amphora, Astellas, Axonics, Boston Scientific, Coloplast, Cook Myosite, Dignify Therapeutics, EBT Medical, FemPulse, Ipsen, Taris, and Uro1 and is a consultant for Allergan, Astellas, Boston Scientific, Coloplast, Laborie, and Urovant Sciences. R A Jankowich was an employee of Urovant Sciences. C Haag-Molkenteller is an employee of Urovant Sciences. The authors report no other conflicts of interest in this work.

\section{References}

1. Irwin DE, Kopp ZS, Agatep B, Milsom I, Abrams P. Worldwide prevalence estimates of lower urinary tract symptoms, overactive bladder, urinary incontinence and bladder outlet obstruction. BJU Int. 2011;108(7):1132-1138. doi:10.1111/j.1464-410X.2010.09993.x

2. Coyne KS, Sexton CC, Vats V, Thompson C, Kopp ZS, Milsom I. National community prevalence of overactive bladder in the United States stratified by sex and age. Urology. 2011;77(5):1081-1087. doi:10.1016/j.urology.2010.08.039

3. Coyne KS, Wein A, Nicholson S, Kvasz M, Chen CI, Milsom I. Comorbidities and personal burden of urgency urinary incontinence: a systematic review. Int J Clin Pract. 2013;67(10):1015-1033. doi:10.1111/ijcp.12164

4. Coyne KS, Sexton CC, Bell JA, et al. The prevalence of lower urinary tract symptoms (LUTS) and overactive bladder (OAB) by racial/ethnic group and age: results from OAB-POLL. Neurourol Urodyn. 2013;32(3):230-237. doi:10.1002/nau.22295

5. Gormley EA, Lightner DJ, Burgio KL, et al. Diagnosis and Treatment of Overactive Bladder (Non-Neurogenic) in Adults: AUA/SUFU Guideline. American Urological Association; 2019.

6. Leron E, Weintraub AY, Mastrolia SA, Schwarzman P. Overactive bladder syndrome: evaluation and management. Curr Urol. 2018;11(3):117-125. doi: $10.1159 / 000447205$

7. Ruxton K, Woodman RJ, Mangoni AA. Drugs with anticholinergic effects and cognitive impairment, falls and all-cause mortality in older adults: a systematic review and meta-analysis. Br J Clin Pharmacol. 2015;80(2):209-220. doi:10.1111/bcp.12617

8. Dmochowski RR, Thai S, Iglay K, et al. Increased risk of incident dementia following use of anticholinergic agents: a systematic literature review and meta-analysis. Neurourol Urodyn. 2021;40(1):28-37. doi:10.1002/nau.24536

9. Benner JS, Nichol MB, Rovner ES, et al. Patient-reported reasons for discontinuing overactive bladder medication. BJU Int. 2010;105 (9):1276-1282. doi:10.1111/j.1464-410X.2009.09036.x

10. Yeowell G, Smith P, Nazir J, Hakimi Z, Siddiqui E, Fatoye F. Real-world persistence and adherence to oral antimuscarinics and mirabegron in patients with overactive bladder (OAB): a systematic literature review. BMJ Open. 2018;8(11):e021889. doi:10.1136/bmjopen-2018-021889

11. Tiisanoja A, Syrjälä AM, Komulainen K, et al. Anticholinergic burden and dry mouth among Finnish, community-dwelling older adults. Gerodontology. 2018;35(1):3-10. doi:10.1111/ger.12304

12. Ganz ML, Liu J, Zou KH, Bhagnani T, Luo X. Real-world characteristics of elderly patients with overactive bladder in the United States. Curr Med Res Opin. 2016;32(12):1997-2005. doi:10.1080/03007995.2016.1226167

13. Herschorn S, Chapple CR, Abrams P, et al. Efficacy and safety of combinations of mirabegron and solifenacin compared with monotherapy and placebo in patients with overactive bladder (SYNERGY study). BJU Int. 2017;120(4):562-575. doi:10.1111/bju.13882

14. Kelleher C, Hakimi Z, Zur R, et al. Efficacy and tolerability of mirabegron compared with antimuscarinic monotherapy or combination therapies for overactive bladder: a systematic review and network meta-analysis. Eur Urol. 2018;74(3):324-333. doi:10.1016/j.eururo.2018.03.020

15. Mitcheson HD, Samanta S, Muldowney K, et al. Vibegron (RVT-901/MK-4618/KRP-114V) administered once daily as monotherapy or concomitantly with tolterodine in patients with an overactive bladder: a multicenter, phase IIb, randomized, double-blind, controlled trial. Eur Urol. 2019;75(2):274-282. doi:10.1016/j.eururo.2018.10.006

16. Staskin D, Frankel J, Varano S, Shortino D, Jankowich R, Mudd PN Jr. International phase III, randomized, double-blind, placebo and active controlled study to evaluate the safety and efficacy of vibegron in patients with symptoms of overactive bladder: EMPOWUR. $J$ Urol. 2020;204 (2):316-324. doi:10.1097/JU.0000000000000807

17. Herschorn S, Barkin J, Castro-Diaz D, et al. A phase III, randomized, double-blind, parallel-group, placebo-controlled, multicentre study to assess the efficacy and safety of the $\beta_{3}$ adrenoceptor agonist, mirabegron, in patients with symptoms of overactive bladder. Urology. 2013;82(2):313-320. doi:10.1016/j.urology.2013.02.077

18. Schena G, Caplan MJ. Everything you always wanted to know about $\beta(3)-\mathrm{AR} *$ (* but were afraid to ask). Cells. 2019;8(4):357. doi:10.3390/ cells 8040357

19. Yamaguchi O. $\beta_{3}$-adrenoceptors in human detrusor muscle. Urology. 2002;59(5 suppl 1):25-29. doi:10.1016/s0090-4295(01)01635-1

20. Nomiya M, Yamaguchi O. A quantitative analysis of mRNA expression of $\alpha 1$ and $\beta$-adrenoceptor subtypes and their functional roles in human normal and obstructed bladders. $J$ Urol. 2003;170(2 Pt 1):649-653. doi:10.1097/01.ju.0000067621.62736.7c 
21. Wachter SB, Gilbert EM. Beta-adrenergic receptors, from their discovery and characterization through their manipulation to beneficial clinical application. Cardiology. 2012;122(2):104-112. doi:10.1159/000339271

22. Lorca M, Morales-Verdejo C, Vasquez-Velasquez D, et al. Structure-activity relationships based on 3D-QSAR CoMFA/CoMSIA and design of aryloxypropanol-amine agonists with selectivity for the human $\beta_{3}$-adrenergic receptor and anti-obesity and anti-diabetic profiles. Molecules. 2018;23(5):1191. doi:10.3390/molecules23051191

23. Edmondson SD, Zhu C, Kar NF, et al. Discovery of vibegron: a potent and selective $\beta_{3}$ adrenergic receptor agonist for the treatment of overactive bladder. J Med Chem. 2016;59(2):609-623. doi:10.1021/acs.jmedchem.5b01372

24. Brucker BM, McHale K, King J, Mudd PN Selectivity and maximum response of vibegron and mirabegron for $\beta_{3}$-adrenergic receptors. Proceedings of the Society of Urodynamics, Female Pelvic Medicine and Urogenital Reconstruction 2021 Winter Meeting: Virtual Congress; February 25-27, 2021.

25. Urovant Sciences, Inc. GEMTESA ${ }^{\circledR}$ (Vibegron). [Prescribing Information]. Irvine, CA; 2020.

26. Rutman MP, King JR, Bennett N, Ankrom W, Mudd PN. Once-daily vibegron, a novel oral $\beta_{3}$ agonist, does not inhibit CYP2D6, a common pathway for drug metabolism in patients on OAB medications. J Urol. 2019;201:e231.

27. Rutman MP, Horn JR, Newman DK, Stefanacci RG. Overactive bladder prescribing considerations: the role of polypharmacy, anticholinergic burden, and CYP2D6 drug-drug interactions. Clin Drug Investig. 2021;41(4):293-302. doi:10.1007/s40261-021-01020-x

28. Takusagawa S, Miyashita A, Iwatsubo T, Usui T. In vitro inhibition and induction of human cytochrome P450 enzymes by mirabegron, a potent and selective beta3-adrenoceptor agonist. Xenobiotica. 2012;42(12):1187-1196. doi:10.3109/00498254.2012.700140

29. Krauwinkel W, Dickinson J, Schaddelee M, et al. The effect of mirabegron, a potent and selective $\beta_{3}$-adrenoceptor agonist, on the pharmacokinetics of CYP2D6 substrates desipramine and metoprolol. Eur J Drug Metab Pharmacokinet. 2014;39(1):43-52. doi:10.1007/s13318-013-0133-1

30. Staskin D, Frankel J, Varano S, Shortino D, Jankowich R, Mudd PN Jr. Once-daily vibegron $75 \mathrm{mg}$ for overactive bladder: long-term safety and efficacy from a double-blind extension study of the international phase 3 trial (EMPOWUR). $J$ Urol. 2021;205(5):1421-1429. doi:10.1097/ JU.0000000000001574

31. Weber M, White WB, King J, Walker A, Mudd PN, Haag-Molkenteller C. Effects of vibegron on ambulatory blood pressure in patients with overactive bladder: results from a double-blind study. Blood Pressure Monitoring. 2021;Epub ahead of print. doi:10.1097/MBP.0000000000000572

32. Frankel J, Varano S, Staskin D, Shortino D, Jankowich R, Mudd PN Jr. Vibegron improves quality-of-life measures in patients with overactive bladder: patient-reported outcomes from the EMPOWUR study. Int J Clin Pract. 2021;75(5):e13937. doi:10.1111/ijcp.13937

33. Varano S, Staskin D, Frankel J, Shortino D, Jankowich R, Mudd PN Jr. Efficacy and safety of once-daily vibegron for treatment of overactive bladder in patients aged $\geq 65$ and $\geq 75$ years: subpopulation analysis from the EMPOWUR randomized, international, phase III study. Drugs Aging. 2021;38(2):137-146. doi:10.1007/s40266-020-00829-z

34. Staskin D, Frankel J, Varano S, et al. Vibegron for the treatment of patients with dry overactive bladder: a subgroup analysis from the EMPOWUR trial. J Urol. 2021;206(suppl 3):e1107-1108. doi:10.1097/JU.0000000000002103.15

35. Newman D, Varano S, Shortino D, Jankowich R, Mudd PN Jr. Efficacy and safety of vibegron for the treatment of overactive bladder in women: a subgroup analysis from the EMPOWUR trial. Female Pelvic Med Reconstr Surg. 2021;27(10S):S1-S129. doi:10.1097/SPV.0000000000001103

36. Varano S, Newman D, Shortino D, Jankowich R, Mudd PN Jr. Efficacy and safety of vibegron for the treatment of overactive bladder in women: a subgroup analysis from the EMPOWUR trial. Proceedings of the International Urogynecological Association Virtual; December 9-12, 2021.

37. Milsom I, Kaplan SA, Coyne KS, Sexton CC, Kopp ZS. Effect of bothersome overactive bladder symptoms on health-related quality of life, anxiety, depression, and treatment seeking in the United States: results from EpiLUTS. Urology. 2012;80(1):90-96. doi:10.1016/j. urology.2012.04.004

Therapeutics and Clinical Risk Management

Dovepress

\section{Publish your work in this journal}

Therapeutics and Clinical Risk Management is an international, peer-reviewed journal of clinical therapeutics and risk management, focusing on concise rapid reporting of clinical studies in all therapeutic areas, outcomes, safety, and programs for the effective, safe, and sustained use of medicines. This journal is indexed on PubMed Central, CAS, EMBase, Scopus and the Elsevier Bibliographic databases. The manuscript management system is completely online and includes a very quick and fair peer-review system, which is all easy to use. Visit http://www. dovepress.com/testimonials.php to read real quotes from published authors.

Submit your manuscript here: https://www.dovepress.com/therapeutics-and-clinical-risk-management-journal 